Cuadernos de Historia Contemporánea

ISSN: 0214-400X

https://dx.doi.org/10.5209/chco.78171

\title{
La balada del norte: Estudio de caso
}

\author{
Alfonso Zapico ${ }^{1}$
}

Recibido: 25 de enero de 2021 / Aceptado: 23 de julio de 2021

Resumen. La balada del norte es una novela gráfica en cuatro volúmenes dedicada a la revolución socialista de Asturias en 1934 y a la singular sociedad donde enraizó. No fue algo heroico ni romántico, ni tampoco condenable: fue más complejo que todo eso. Suena a balada final, a homenaje de despedida y cierre de alguien ensamblado en una cultura industrial que camina hacia la extinción.

Palabras clave: Cómic; Revolución; Memoria; Asturias; Octubre.

\section{[en] The ballad of the North: a case study}

\begin{abstract}
The ballad of the North is a graphic novel in four volumes about the socialist revolution in Asturias of 1934 and the unique society in which it took told. It was something neither heroic nor romantic nor condemnable: it was more complex than all of that. It sounds like a final ballad, a farewell tribute to an industrial culture - mining- that is on the brink of extinction.
\end{abstract}

Keywords: Comic; Revolution; Memory; Asturias; October.

Sumario. Introducción. 1. La revolución de octubre, ¿antesala de la Guerra Civil? 2. Tetralogía de una revolución. 2.1. Los personajes. 2.2. Un escenario ficticio y real a la vez. 3. Estilo gráfico de la narración. 4. Documentación, inspiración e influencias. 4.1. Documentación oral y escrita: mezcla de realidad y ficción. 4.2. Documentación gráfica.

Cómo citar: Zapico, A. (2021). La balada del norte: Estudio de caso. Cuadernos de Historia Contemporánea, Vol. 43, 73-87.

\section{Introducción}

La revolución de octubre de 1934 estalló en toda España en forma de huelga general revolucionaria. Tuvo especial virulencia en los territorios obreros del norte, y alumbró una efímera y malograda Cataluña independiente dentro de un supuesto Estado federal español que nunca fue. La revuelta, que vino a morir casi sin apenas haber nacido en la mayor parte del territorio nacional, desembocó en la región minera de Asturias en una verdadera revolución, prolongándose los "sucesos de Asturias" durante casi dos semanas y dejando tras de sí la capital de provincia en ruinas y millares de muertos y represaliados.

\footnotetext{
$1 \quad$ Autor de cómic, Premio Nacional de Cómic 2012.

E-mail: hola@alfonsozapico.eu
} 
La balada del norte es una novela gráfica en cuatro tomos (el cuarto libro de la serie aparecerá en 2022) que empecé a dibujar en 2012. Ese mismo año llegó una noche de verano a Madrid una "marcha negra" de mineros asturianos, leoneses, palentinos, aragoneses, manchegos. Reivindicaban un futuro para las cuencas mineras españolas, y defendían en solitario la viabilidad económica del carbón nacional; fue el canto del cisne de un mundo que desaparecía barrido por la descarbonización europea y las leyes inexorables del mercado.

En las casi 1200 páginas que tendrá finalmente La balada del norte en sus cuatro tomos, rescato ese mundo y lo dibujo en el contexto histórico de 1933-1934 (el último tomo llega hasta principios de 1935). El objeto de la historia no es tanto revisar los hechos acontecidos durante la llamada "Comuna asturiana" (hecho histórico que bien merece una revisión aunque solo sea para salvarlo del olvido), sino la recreación de la sociedad que los provocó, los vivió en primera línea y sufrió sus consecuencias. El lector descubre la historia a través de un crisol de personajes arquetípicos ubicados en un marco geográfico ficticio (Montecorvo) que resulta de una mezcla de lugares identificables de las dos cuencas mineras asturianas (la cuenca del Nalón y la cuenca del Caudal). ¿Cuál es el objetivo de este proyecto casi galdosiano, donde las historias individuales ocupan más espacio que la Historia (cuyo espacio se reserva a los titulares de prensa o las crónicas radiofónicas) con mayúsculas? Uno tan simple como necesario: rescatar la memoria y la identidad de los protagonistas de una revolución olvidada.

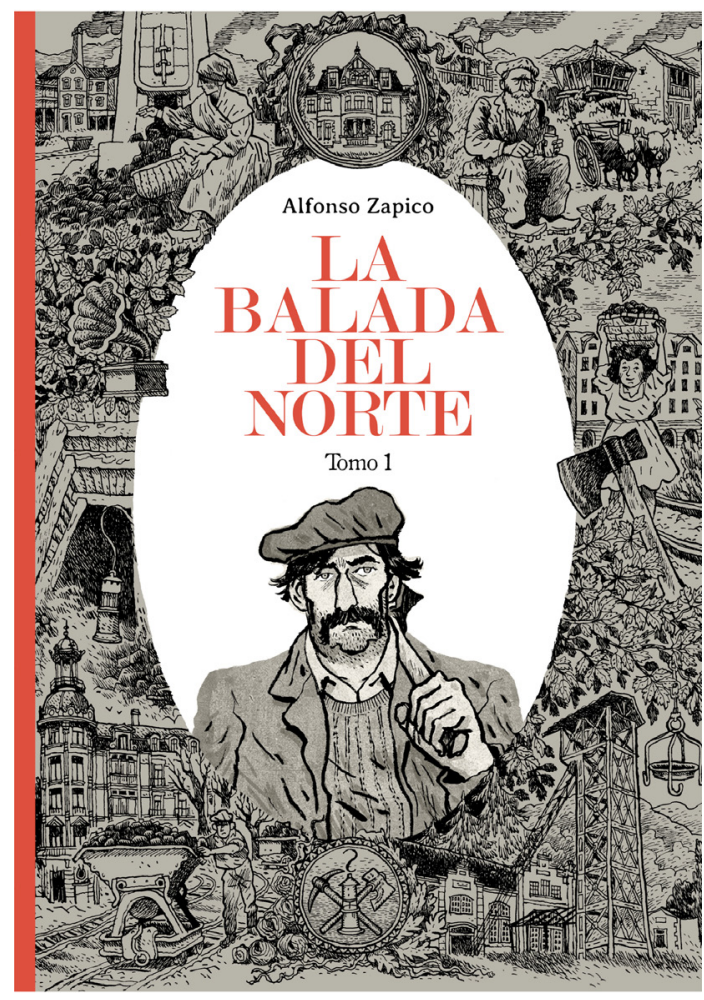

Figura 1. Portada de La balada del norte. Tomo 1 


\section{La revolución de octubre, ¿antesala de la guerra civil?}

Uno de los lugares comunes cuando se discute sobre la Guerra civil española es justificar el golpe de estado de los militares africanistas en 1936 por contraste a la Revolución de 1934. Según esta opinión generalizada en los sectores derechistas o ultraderechistas de España, y cuyo origen se remonta al propio conflicto, la Guerra civil comenzó durante el "octubre asturiano", cuando los socialistas, con Largo Caballero a la cabeza, intentaron derribar al gobierno republicano de Lerroux (justo en el momento en el que entraban en el gabinete ministerial tres hombres de la C.E.D.A. de Gil Robles, lo que provocó la revuelta). La balada del norte no busca indagar en la pertinencia o no de tal teoría, al autor no le interesa defender aquello o lo contrario, ni mucho menos blanquear una revolución proletaria o elevarla a la categoría de mito. El movimiento revolucionario de 1934, como todos los que lo precedieron en la historia, nació acompañado de una brutal violencia. En él participaron elementos fuera de control que cometieron crímenes injustificables (algunos ejemplos de esto aparecen en los tomos 1 y 2). Esta novela gráfica intenta, más bien, contextualizar este movimiento, explicar al lector el tiempo que precedió a su comienzo, recrear las vivencias de algunos de sus protagonistas, históricos o anónimos, y dejarse llevar al final por la capacidad narrativa que nos permite ese artefacto en el que se mezclan realidad y ficción sin que a veces el lector pueda separar ambas materias, y que llamamos novela.

Aparte, en mi opinión personal de autor de cómic (no una opinión de historiador, investigador o protagonista directo de los hechos) el simple hecho de justificar el golpe de estado franquista contraponiéndolo con la revolución de octubre de 1934 delata una ignorancia interesada, ya que, dejando de lado análisis más precisos, obvia la diferencia más flagrante: la insurrección de 1934 fue protagonizada por obreros y sindicatos que sufrían en carne propia las injusticias de una época feroz, y el golpe de 1936 lo ejecutaron militares, dirigentes políticos y terratenientes que temían perder la capacidad de sojuzgar a los primeros.

\section{Tetralogía de una revolución}

La balada del norte consta de cuatro tomos, aunque inicialmente estaba pensado para ser un libro único con el formato de narración clásica de introducción + nudo + desenlace. Pero cada una de estas partes necesitaba tantas páginas para ser bien contada, que se convirtió en un libro completo. Como el tercer tomo, en el que se suponía que había de llegar el desenlace, fue alargándose progresivamente en su desarrollo, decidí con el editor Astiberri convertir la trilogía prevista en una tetralogía, conjunto del todo inusual y hasta poco deseable de cara al mercado editorial español, pero inevitable para llevar a buen puerto la historia. Para el editor francés (Futuropolis, que ha traducido ya los 3 primeros tomos pero aún no ha publicado ninguno) resulta más práctico reducir los 4 libros a 2 , pero aún espera a la finalización del último tomo de La balada del norte para no dejar pasar más de 6 meses entre cada tomo (en España aparecen periódicamente cada 2 años, pero los tiempos son diferentes).

- El primer tomo de La balada del norte es una introducción para el lector. Comienza con un pequeño capítulo de preámbulo que arranca en la Guerra de 
Marruecos, el advenimiento de la II República y el contexto histórico europeo. Se explica la etapa inicial de la República: un período de cambios sociales y vorágine, y la historia comienza en la Navidad de 1933, tras las elecciones que dieron un vuelco a las aspiraciones de progreso para estancarse en el gobierno Lerroux, que no tardará en deshacer el camino andado. A partir de aquí serán los personajes protagonistas los que explicarán los acontecimientos viviéndolos en primera persona. Este libro 1, en el que no hay Revolución, permite al lector descubrir por qué estalla la revuelta descrita en el libro 2. Las penosas condiciones de trabajo en las minas de carbón de Asturias, la miseria imperante, la degradación de la convivencia, la influencia poderosa de la Revolución rusa de 1917, el escaso valor de la existencia y la falta de horizontes y de confianza en el porvenir se dibujan en las viñetas de este primer libro.

- El tomo 2 de La balada del norte es la narración ininterrumpida de la revuelta: desde los primeros enfrenamientos en las cuencas mineras hasta la capital, siguiendo el recorrido de los protagonistas, con referencias puntuales a otros lugares de Asturias o León, y a la situación general en el país. Las casi 300 páginas de la segunda parte corresponden a las dos semanas que duró la "Comuna asturiana".

- El tomo 3 es la narración de la derrota y desintegración de aquella insurrección efímera. Los sueños de "revolución social" dejan paso a la huida a las montañas y a la represión en cárceles improvisadas por toda la región, que acababa muchas veces en ejecuciones al margen de la ley. El desenlace de la Historia llega aquí, pero falta aún por saber el desenlace de los personajes protagonistas de la saga, que llegará en el cuarto tomo, aún en proceso de realización.

\subsection{Los personajes}

He creado un crisol de personajes, algunos de los cuales son auténticos protagonistas de la historia y acompañan al lector, y el resto son secundarios que aparecen o desaparecen ajustándose a las necesidades narrativas. Igual que sucede en las novelas clásicas rusas o en los Episodios Nacionales de Galdós, si el lector quiere enterarse de la historia debe prestar atención a los diálogos (en este caso, a los globos de texto). Hay cuatro protagonistas principales, pilares de la novela gráfica:

- Amadeo Valdivia, marqués de Montecorvo, propietario de la Compañía minera del Noroeste. Es un hombre mayor y combativo, un empresario de la vieja escuela que rige los destinos de sus trabajadores con mano de hierro. Este personaje está basado en parte en la figura paternalista del industrial minero Claudio López Bru, II marqués de Comillas.

- Tristán Valdivia, hijo único del marqués. Rebelde y hedonista, periodista sin éxito en Madrid, editor de poesía rusa, vividor e izquierdista puntual sin mucha convicción. Regresa al norte gravemente enfermo.

- Apolonio, picador en la mina Santa Aurelia, propiedad del marqués. Arquetipo del obrero bruto y noble, ansía más que lo dejen en paz que una revolución social, pero acabará sumándose al movimiento (como tantos otros) por pura inercia, por rabia, por desánimo. 
- Amalia, la mujer de Apolonio, es carbonera en un cargadero de la mina, donde apalea mineral a los vagones. Es una mujer sencilla y de buen corazón, que ha perdido dos hijos y no se interesa por la política.

- Isolina, la hija de Apolonio, es una joven avispada y sagaz. Trabaja como criada en el palacete del marqués, y allí conoce a Tristán. Orgullosa y bruta como su padre, su relación con el hijo del marqués no parece factible en una época como la que se recrea en La balada del norte, pero surge como recurso literario de primer orden para conectar estos dos mundos próximos a chocar el uno contra el otro.

Otros personajes secundarios, algunos históricos y otros de ficción, inundan las páginas de la novela gráfica. He aquí una pequeña lista de los más importantes:

Personajes de ficción (aunque basados en personajes reales)

- Sandalio, el mejor amigo de Apolonio, es socialista y forma parte del Sindicato minero, uno de los motores de la revolución.

- Falín, ayudante minero sin mucho talento para el oficio (y sin mucha suerte).

- La camarilla del marqués, formada por otros dos empresarios mineros y el juez Portillo, aparecen en el libro 1 (el juez Portillo tiene un papel destacado) para reaparecer en el libro 4 (con la revolución ya vencida).

- Los mineros y las carboneras ofrecen un retrato colectivo de la clase obrera de la época: obreros endeudados y violentos, mujeres que trabajan durante jornadas interminables mientras sostienen las familias, niños que pasan de la escuela a la mina sin apenas saber leer.

- Los guardias civiles y guardas jurados de las minas, no aparecen en la obra como personajes arquetípicos: los guardias desesperados y profundamente humanos que caen en el puesto de Sama del libro 2 poco tienen que ver con la tropa vengativa al mando del comandante Doval (libro 3). Mención aparte merece la recreación en 4 páginas de los regulares moros (libro 3), de los que se habla recurrentemente durante toda la historia; a los moros se los desprecia y se los teme, se recuerda su ferocidad durante Annual y la guerra de Marruecos, se intenta evitar a toda costa que pongan un pie en las cuencas mineras. Pero pocas veces se ha dado voz a esta tropa extranjera en un difícil ejercicio de empatía. ¿Quiénes eran? ¿Por qué se enrolaron en la tropa colonial? ¿Cuáles eran sus horizontes vitales?

- Los periodistas del diario LA NOTICIA, vinculados a Tristán a través de un reporterismo de tiempos pasados que apenas conocemos. Este periódico es un reflejo fiel del diario $A V A N C E$, que pertenecía al Sindicato minero y estaba dirigido por el madrileño Javier Bueno. Algunos de los periodistas reales del diario, como Jesús Ibáñez (aquí Ordóñez) u Ovidio Gondi aparecen dibujados en estas viñetas. Los titulares incendiarios de AVANCE contribuyeron al estallido de la revuelta, y sus redactores pasaron de la cárcel al frente en la Guerra civil, donde casi todos fueron muertos. Las rotativas del diario fueron confiscadas tras la caída de Asturias y continuaron imprimiendo un nuevo diario al servicio del régimen, La Nueva España.

- Los curas aparecen en la obra, primero como parte de una sociedad casi medieval (el cura de Montecorvo lleva pistola, anécdota real) y después como 
víctimas de la violencia descontrolada de algunos revolucionarios (libro 2). No he profundizado mucho en la relación contrapuesta de aquellas gentes con la religión. Numerosas congregaciones católicas estaban establecidas en los valles mineros, dedicadas a la educación de los hijos de los trabajadores. Cuando estalló la revolución de octubre, se produjeron varios asesinatos entre frailes y sacerdotes, que algunos achacaron al odio que los mineros profesaban a los hombres del clero (que ejercían también una labor de control de los trabajadores más subversivos) y otros justificaron con una patológica aversión a los frailes por parte de socialistas y comunistas.

- Los militares que intervienen en la pacificación de Asturias aparecen también puntualmente, muchas veces tan ignorantes de lo que sucede y del futuro como los propios revolucionarios (muchos eran reclutas de cuarteles de Castilla y León).

- La burguesía de Oviedo, que ve como su vida ordinaria salta por los aires cuando los mineros entran en la capital a sangre y fuego, aparece sobre todo en el libro 2. Es la familia de Pompilio Piñón, el abogado de la Ferroviaria, la que representa de una forma arquetípica a este grupo social, cómodo con la coyuntura política, católico practicante y poco dado a mezclarse con la chusma obrera de las villas industriales.

- En el libro 4 aparece un nuevo grupo de personajes que tendrá protagonismo el resto de la obra: son los rebeldes huidos al monte, los "fugaos", como se les conocerá popularmente en Asturias, sobre todo a partir de 1938 (cuando el frente norte cae durante la Guerra civil). El fenómeno de los "maquis" a la asturiana existió de forma minoritaria tras la revolución de octubre y tuvo su auge en la posguerra española hasta 1952).

Personajes reales (aunque dibujados con toques de ficción)

- Belarmino Tomás y Ramón González Peña aparecen en varios tomos. Vinculados al PSOE, fueron los cabecillas de la revuelta en Asturias, y volvieron a interpretar un papel casi idéntico durante la Guerra civil (con idéntico final).

- Francisco Largo Caballero e Indalecio Prieto tuvieron un papel destacado en la revolución, y el desenlace trágico de la misma cristalizó en una división del PSOE, acentuada en 1936. Largo Caballero aparece en los libros 1, 2 y 4. Prieto al principio (en los titulares de prensa) y al final.

- El capitán Alonso Nart era el oficial al mando del cuartel de la Guardia Civil de Sama de Langreo. Cayó defendiendo la plaza, y a día de hoy la calle donde estaba emplazado el edificio lleva su nombre. Al final del libro 3 se hace alusión a la participación de su hermano, un tal teniente Nart, en la represión.

- Los generales Franco, Yagüe y López Ochoa tienen un papel breve pero trascendental, que había que mostrar al lector en los sucesos de 1934. Dibujo una recreación de dos encuentros en dos momentos puntuales de la revolución: la conversación de Franco con el ministro de la Guerra Hidalgo y la negociación al final del conflicto entre Belarmino Tomás y López Ochoa para pactar la rendición (aquí aparece un improbable encuentro con Yagüe).

- A través del recurso de la página doble dedicada a los periódicos (obreristas o burgueses) se ofrece al lector declaraciones reales de personajes históricos (Lerroux, Gil-Robles, Prieto...). La página doble del Congreso de los dipu- 
tados en Madrid del libro 3 también incrusta en los globos de texto las aportaciones recogidas en el diario de sesiones (Melquiades Álvarez, Francesc Cambó, Calvo Sotelo, Hidalgo....).
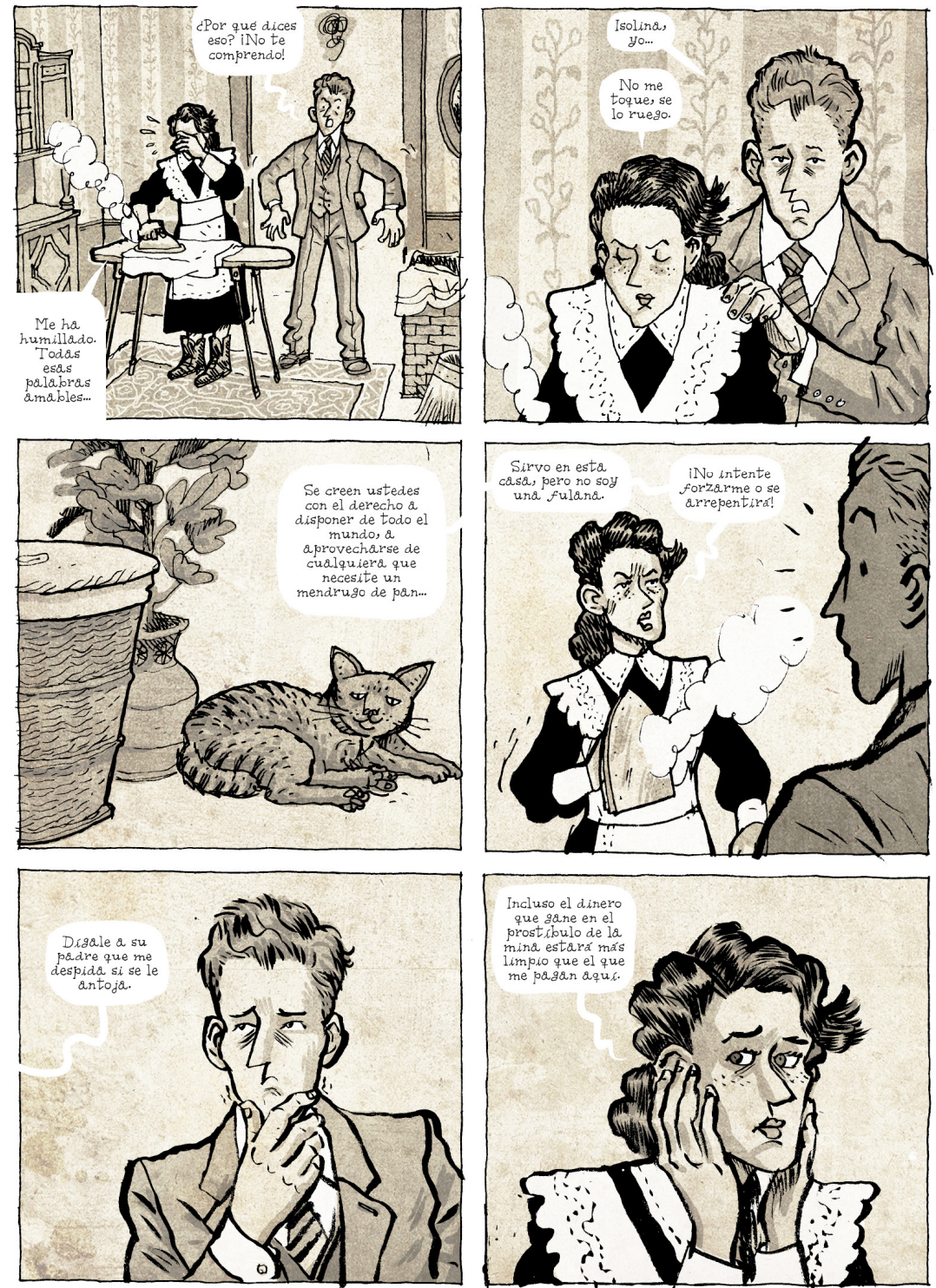

Figura 2. Página de La balada del norte. Tomo 1 (en el color sepia original)

\subsection{Un escenario ficticio y real a la vez}

Desde el principio concebí unos protagonistas de ficción, para poder manejarlos libremente dentro de un evento histórico (la Revolución de 1934). Pero necesitaba un 
escenario en el que situarlos para poder explicarlos, para que el lector comprendiera el contexto, para poner en marcha los mecanismos narrativos de una novela clásica en viñetas. Para no limitarme ni suscitar prejuicios localistas, decidí (como tantos autores han hecho tantas otras veces) crear mi propio pueblo minero, Montecorvo del $\mathrm{Ca}$ mino. Esta villa industrial enclavada en una zona rural hibrida los dos valles mineros (Langreo y Mieres). Y para crear ese territorio utilicé, como los juegos de bloques de construcción, elementos gráficos extraídos de diferentes lugares. Algunos ejemplos:

- La mina Santa Aurelia es en realidad el Pozo San Luis de La Nueva (Langreo)

- El palacete del marqués es en realidad el Chalet de los Figaredo (Turón), familia propietaria de la compañía Minas de Figaredo

- El poblado minero del que se ofrece una vista cenital en el libro 3 es el poblado de Bustiello (Mieres)

- El puente minero que aparece en el libro 3 no cruza a Montecorvo sino a Blimea (San Martín del Rey Aurelio)

- El cargadero de carbón de Montecorvo está situado en La Hueria Carrocera (S.M.R.A.)

Por un lado, utilizar elementos emblemáticos de las cuencas mineras me permite presentar el territorio al lector no familiarizado. Por otro lado, para los lectores que sí lo conocen, se evita la tentación de caer en localismos. Después de todo, las Cuencas mineras de Asturias son un espacio más sentimental que geográfico, que no se explica por sus límites territoriales, su lengua o el origen de sus habitantes. Esta sociedad de fuertes valores identitarios, que se han mantenido a lo largo de la historia, está basada en el trabajo: los pozos y los lavaderos de carbón dan sentido a la existencia de sus gentes, y mineros y carboneras son oficios que se heredan generacionalmente. La inmigración es absorbida e integrada en la vorágine de la industria, y surge aquí (y desaparece hoy) una especie de nacionalismo no excluyente, al que se adhieren trabajadores de las más diversas procedencias, de ideologías encontradas y que hablan con acento desigual.

El cómic recrea otros escenarios, estos sí, ya reales, como la Gijón industrial de 1933 (en la villa de Gijón se teje la alianza entre los socialistas de las minas de carbón y los anarquistas de las fábricas).

Aparece también la capital de la provincia, Oviedo, que tendrá un protagonismo fundamental en la novela gráfica y en la propia Revolución. Oviedo ejercerá como polo de atracción de las columnas obreras, que pugnarán por conquistarla hasta la llegada del ejército, y regresarán a las cuencas mineras sin conseguirlo. La destrucción trágica de una gran parte de la ciudad convertirá a Oviedo en "ciudad mártir" para la propaganda del gobierno de Lerroux, que achacará a los rebeldes hechos como el incendio del Teatro Campoamor (dibujado en el libro 2) o la destrucción de la biblioteca de la Universidad.

Otros escenarios secundarios, como el norte de León, Bembibre o Madrid (una sesión del Congreso de los Diputados en el libro 3) tienen un espacio en la narración. También aparece brevemente Barcelona durante la proclamación del presidente Companys en el balcón del Palau de la Generalitat y la consiguiente reacción del general Batet, que sacará sus tropas a la calle para sofocar la efímera insubordinación.

Los cuatro libros están documentados gráficamente para dar una sensación de verosimilitud, pero no pueden considerarse un ensayo o un ejercicio de periodismo 
dibujado. No se trata de una simulación del hecho histórico, sino de una recreación. La diferencia es sutil pero importante, porque, no dejando de ser una novela gráfica, mi objetivo principal es sumergir al lector en la historia, hacerla creíble, verosímil, lo más real posible. Pero sin prestar más atención de la necesaria a los pequeños detalles que integran la historia (en el libro 1, por ejemplo, la fachada del teatro Campoamor no se corresponde con la de 1934, error subsanado en el libro 2).
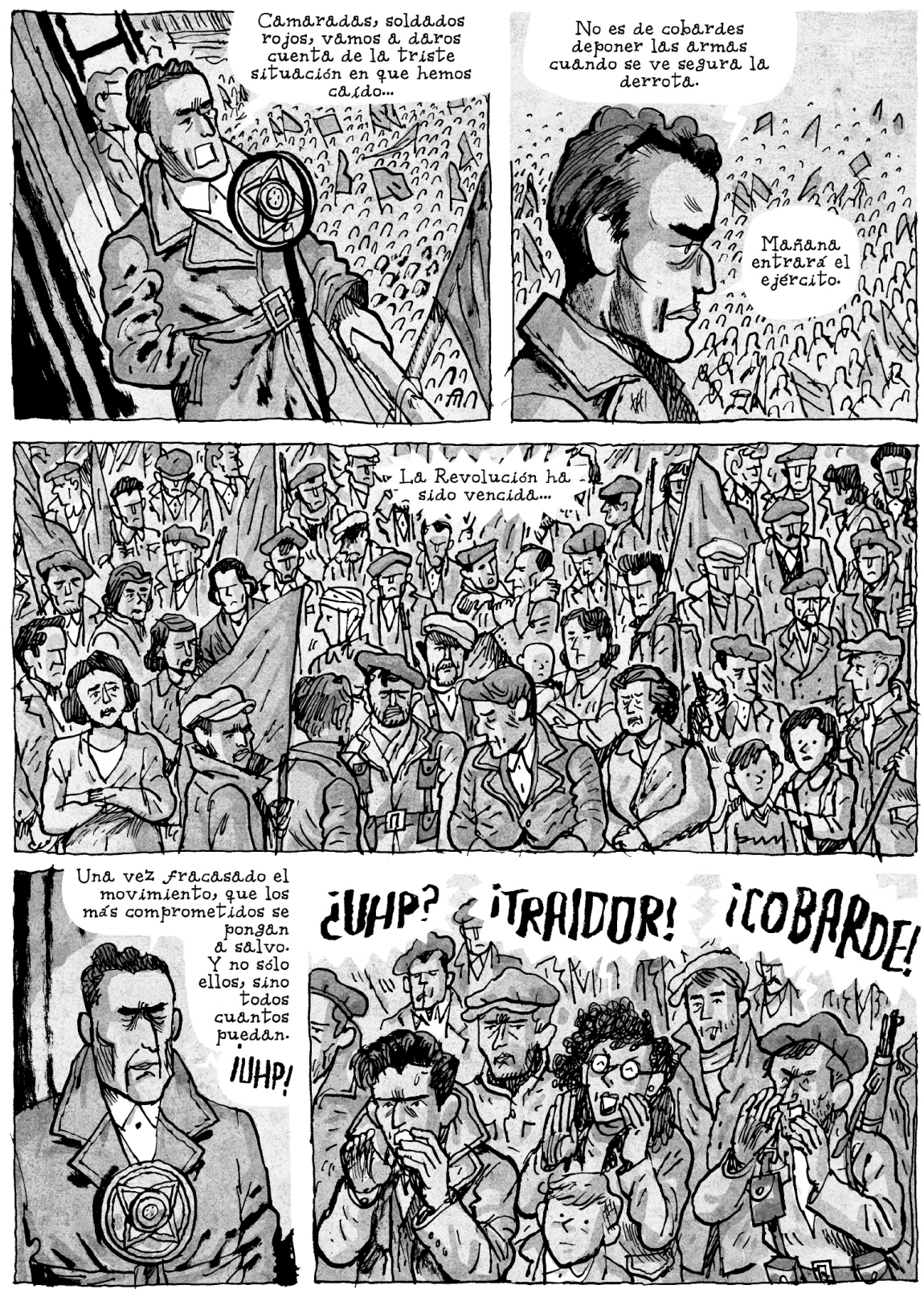

Figura 3. Página de La balada del norte. Tomo 3 


\section{Estilo gráfico de la narración}

Gráficamente, esta novela gráfica en 4 tomos supone una evolución desde títulos anteriores como Dublinés (2011) o El otro mar (2013). Para el proceso de dibujo, nada ha cambiado desde que dibujé mi primer cómic en 2006: aboceto las páginas con lápiz azul (cuya ventaja es que desaparece en el proceso de escaneado y no hace falta borrarlo) para luego trazar el dibujo definitivo con tinta china, aplicada con plumilla y pincel sobre papel Canson de 180 gramos.

Partiendo de la línea gráfica utilizada en la biografía dibujada de James Joyce, decidí en La balada del norte abandonar la aguada de grises para colorear las viñetas, proceso que me daba muchos problemas en la digitalización de las páginas. Además, los errores en el coloreado con aguada son muy difíciles de subsanar sobre la propia plancha. Opté entonces por el color digital, pero con una textura de papel viejo. Para lograr los diferentes tonos de gris aplico digitalmente un filtro que oscurece el tono de color, y el resultado final es muy similar al que tenían las ilustraciones de los periódicos o magazines de los años 30 .

El mecanismo narrativo de este cómic es muy clásico, apenas hay elementos innovadores de lenguaje secuencial; he optado por una estructura básica de 3 líneas por página, en la que cada línea puede tener de una a cuatro viñetas (raramente cinco o más). Abundan también, sobre todo en las páginas dobles en las que apenas hay texto, las estructuras de página única o de página partida por la mitad, si tengo una necesidad de transmitir información relativa a un escenario urbano o un paisaje, y puedo prolongar esta estructura durante una doble página.

La acción está dividida en capítulos, que están numerados pero no tienen título, y cuya página impar (la primera página de cada capítulo) es una ilustración única que hace referencia a alguna historia contenida en dicho capítulo (los capítulos de $\mathrm{La}$ balada del norte no contienen historias que suceden en un único entorno a un único grupo de personajes, sino que la acción puede saltar en el tiempo o en el espacio tras cada doble página).

Para los bocadillos de texto empleo una tipografía digital directamente en el ordenador. Los dibujantes franceses con los que trabajo en Angoulême continúan escribiendo los textos a mano en los globos en la plancha original. Aprecio la técnica en su artesanía, pero es muy incómoda para mí, porque reviso continuamente la historia antes de enviarla al editor, corrigiendo textos aquí y allá, eliminando bocadillos, añadiendo información o más diálogos... Mi historia está viva a nivel de texto hasta el último momento, y no puedo permitirme reescribir cada bocadillo en papel, escanear y acoplar en la viñeta. Pero tampoco me apetece utilizar una tipografía digital prefabricada, que un lector asiduo de tebeos encontrará quizá en otro cómic antes o después (utilicé estas tipografías digitales para mis primeros álbumes). Así que he creado mi propia letra manuscrita en formato digital, recurso muy de moda hoy entre la mayoría de dibujantes. Tiene la ventaja de que personalizamos nuestras historias con nuestra letra y a la vez podemos modificar libremente el texto. Otra ventaja de crear nuestra propia tipografía es que, cuando un libro vende sus derechos de traducción (La balada del norte ya se está traduciendo a francés y sueco) con las páginas de cómic el editor puede ceder también la tipografía digital del autor, y así, por ejemplo, La balada del norte verá la luz en francés con mi tipografía manuscrita (sin necesidad de que yo escriba todos los textos en francés de nuevo). 


\section{Documentación, inspiración e influencias}

Son muchas las fuentes de las que he bebido para fabricar este artefacto gráfico en 4 partes titulado La balada del norte. Una gran parte de ellas vienen de la literatura (o del periodismo literario) y su reflejo lo encontrará el lector sobre todo en la forma de recrear una época histórica y en los diálogos de los personajes. Otra parte viene del cómic, sobre todo del cómic franco-belga, sobre todo del cómic francés de Jacques Tardi.

De los textos que he utilizado para construir la novela gráfica hablaremos después. Pero habría que hacer referencia a otros libros que, no sirviendo directamente al propósito de recreación de un tiempo y un lugar, o no dándome información sobre el hecho histórico a tratar, sí han sido de gran utilidad para la construcción de los personajes, de los diálogos, del ambiente social de la época y de la forma de pensar de los protagonistas. Algunos, como La forja de un rebelde (1940) de Arturo Barea o El blocao (1922), de José Díaz Fernández, tratan con detalle la Guerra de Marruecos, conflicto que envenenó la política española de los años 20 y que no quiero perder de vista para dibujar la revolución asturiana, ya que explica el sentimiento de hartazgo de la sociedad española (y explica la evolución política, la dictadura de Primo de Rivera y aún la desintegración borbónica). Otras obras, de carácter técnico, como la Colección de artículos industriales acerca de las minas de carbón de Asturias (1888) de Francisco Gascué, me permiten comprender mejor la situación de las compañías mineras en la región a finales del XIX, que no cambiaría sustancialmente en los años 30, y que podría resumirse en una frase: obtener el máximo beneficio posible con la mínima inversión necesaria. Esto también explica, en parte, la revolución.

He consultado varias obras dedicadas al "octubre asturiano" de 1934. Cuanto mayor es su antigüedad, menos es capaz el lector de percibir un relato neutro y veraz de los hechos. Los relatos del exilio de militantes cenetistas, comunistas y socialistas dedican más energía a culpar a los otros del fracaso de la rebelión que a ofrecer un relato imparcial (encontramos un ejemplo de esto en las memorias de Largo Caballero, en las que se emplea con más brío en culpar de sus males a Indalecio Prieto que en explicar su posición). El relato oficial del gobierno republicano tiene aún menos valor, ya que es una mezcla de propaganda y manipulación sin apenas valor documental. Incluso los relatos periodísticos recientemente editados Tres periodistas en la Revolución de Asturias ofrecen tres voces de diferente modulación: Josep Pla no muestra ninguna simpatía (ni empatía) con los revolucionarios, Chaves Nogales trata con dureza a unos y a otros (igual que haría durante la Guerra civil) y José Díaz (autor de El blocao) narra los acontecimientos con una mezcla de pena y comprensión debido a su raigambre asturiana.

Para tener una fotografía completa del paisaje he acudido a historiadores que he juzgado más fiables, como David Ruiz, Paco Ignacio Taibo II o Javier Rodríguez Muñoz.

Una parte de la documentación dibujada en La balada del norte proviene de otras fuentes de documentación menos formales: obras en las que hay más sentimiento que datos fiables, como El valle negro (1979) de Alfonso Camín (periodista asturiano en Madrid en 1934), que recrea los episodios más dramáticos de forma novelada, casi poética, siempre tomando partido por la causa revolucionaria.

También he extraído anécdotas y personajes que estoy dibujando en el libro 4 de una particular autobiografía: las Memorias de Ángeles Flórez Peón, joven adolescente en 1934 (hoy aún viva y centenaria) y cuyo hermano Antonio fue una de las víctimas de 
la "masacre de Carbayín", una ejecución extraoficial de prisioneros. El testimonio de esta mujer es valiosísimo y me ha inspirado para recrear "la cara B" de la revolución en las viñetas de La balada del norte. Esto es: las conversaciones en las cocinas de carbón que sostenían las mujeres, viudas, hijas o huérfanas de los sublevados en prisión o muertos. En sus recuerdos se revela el papel de la mujer en una sociedad profundamente hombruna como era la de las cuencas mineras. Aquellas mujeres, que trabajaban en los cargaderos de carbón o eran matronas, maestras de pueblo, administraban bares o tiendas de ultramarinos, ¿qué pensaban de la situación política? ¿qué pensaban del futuro? ¿cuál era su filiación política? ¿cuál fue su rol en la sociedad militarizada y profundamente herida de la derrota revolucionaria? A través del testimonio de Ángeles, que sería conocida popularmente como "Maricuela" durante la Guerra civil por el nombre de uno de los personajes que interpretaba en una compañía teatral amateur (y que gozaba de gran éxito entre las milicias republicanas) descubro un elemento muy importante en el cómic: la familia. Pero no la familia de Ángeles específicamente, sino el "modelo" de familia minera, de familia como núcleo vital en las Cuencas mineras, donde el arquetipo de familia tradicional carece de sentido. Las familias de la gente que habitaba los valles mineros de Asturias en los años 30 eran tan caóticas como la propia existencia: padres separados, progenitores que desaparecían y emigraban a Cuba, madres que enviudaban y aceptaban empleos misérrimos cargando carbón o cohabitaban con otros mineros viudos, hijos a los que era imposible mantener y eran abandonados o se dejaba al cuidado de otros parientes, familias o incluso vecinos. Esta novela gráfica me ofrece la oportunidad de explicar una de las peculiaridades de la sociedad minera (que existe hasta el día de hoy): el de las redes solidarias que van más allá de los lazos de sangre. Estas redes se tejieron en los sindicatos mineros y en las barriadas, donde sobre todo las mujeres (que eran las que tenían una situación más frágil) construyeron una especie de sororidad primitiva en base a la asistencia mutua. Los capítulos del libro 4 en los que se expone este nuevo concepto de familia provienen, sobre todo, de las memorias de Ángeles.

\subsection{Documentación oral y escrita: mezcla de realidad y ficción}

El primer libro de La balada del norte fue publicado en 2015. En una presentación en una librería de Salamanca en 2016, charlando sobre el episodio histórico y su tratamiento en forma de cómic, un señor anónimo me contó una anécdota vivida en primera persona. Al parecer su padre, que en 1934 era recluta en un cuartel de infantería de Valladolid, fue movilizado y enviado al norte a sofocar la rebelión, y por las noches confundía el brillo de las luciérnagas con la lumbre de los cigarrillos de los mineros, prestos a prender la mecha de sus cartuchos de dinamita. Esta anécdota, de la que no tengo constancia de una veracidad mayor que el simple hecho de haberla escuchado directamente del hijo de su protagonista, me fascinó. La utilicé en el libro 2 de La balada del norte (publicado en 2017) y cuando regresé en 2019 a la misma librería para una nueva conferencia, me encontré de nuevo con aquel hombre, que me estrechó la mano, porque habíamos preservado y compartido, de alguna forma, un fragmento de la memoria de su padre.

Esa especie de rol que desempeño mientras dura la realización de la historia, el rol de depositario de la memoria de otros, es uno de los motores de mi obra. El primer libro fue el más difícil, porque la Revolución de 1934 no deja de ser un tema 
complejo y contradictorio, al que durante muchos años se ha dado la espalda desde izquierda y derecha. Pero una vez publicado el libro, y siendo España un país con
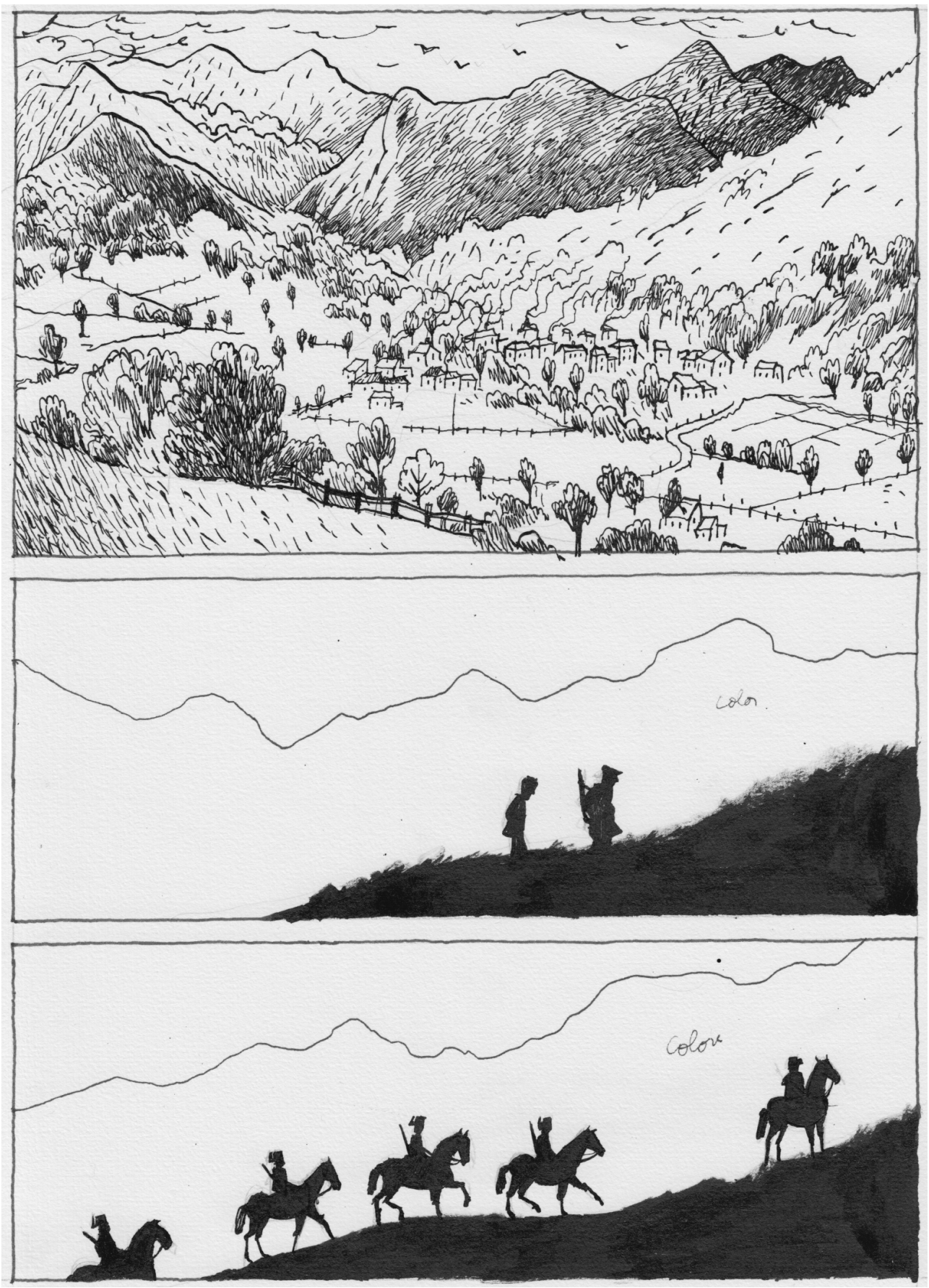

Figura 4. Página a lápiz y tinta de La balada del norte. Tomo 4 (en proceso) 
un enorme "déficit de memoria", se produce un extraño fenómeno; los lectores descubren en las viñetas de La balada del norte experiencias, recuerdos o anécdotas que se asemejan mucho a sus propias vivencias o a las vivencias de sus padres o abuelos. Con la publicación de cada libro me llegan más testimonios, más recuerdos de personas que se sienten concernidas por la historia, que se ven en la obligación de comunicarme un hecho familiar que consideran importante. Así que me he decidido a veces a incrustar esas anécdotas en las conversaciones de los personajes. Dos ejemplos ilustrativos son la página doble dedicada al "Cristo rojo de Bembibre", que el periodista Carlos Fidalgo me contó en la Feria del libro de Madrid durante la promoción del libro 2, y apareció inevitablemente en el libro 3. O el personaje del boticario de la farmacia Nart, que cosía cabezas de anarquistas y socialistas tras las trifulcas obreras habituales en Langreo. Fue el propio bisnieto del farmacéutico, el periodista y político Javier Nart, quien me contó esa historia (Nart es pariente del oficial de la Guardia civil del libro 2). Los recuerdos dibujados son una constante en La balada del norte. Este tipo de documentación no es formal, no está comprobada, no hay registros de fechas ni publicaciones. Pero la aprecio si la juzgo auténtica y útil para retratar un mundo, el mundo que me he comprometido a dibujar y entregar a los lectores.

Y finalmente, como La balada del norte es una novela, me permito las licencias de las que disponen los novelistas. Una de ellas es la de partir de algo real y mezclarlo con ficción. Quizá el mejor ejemplo de esta técnica sea la historia de Ivanov, el oficial legionario que asesina a un periodista en el libro 3. Esa historia es estrictamente real y está documentada, con la diferencia de que el legionario era búlgaro y no ruso. El periodista asesinado en medio del caos represivo de la revolución de octubre se llamaba Luis Higón (firmaba como Luis de Sirval en El Heraldo). El resto es literatura.

\subsection{Documentación gráfica}

Si hay un autor de cómic que haya trazado un camino que yo he seguido (en parte) para dibujar La balada del norte, sería el francés Jacques Tardi (Valence, 1946). Sin llegar al nivel de detalle de este dibujante hiperespecializado en la primera parte del siglo XX y, sobre todo, en la Grande guerre (1914-18) admiro en Tardi su amor por la documentación histórica, por la recreación de una escena, por la construcción tridimensional de sus personajes. Y, sobre todo, por su capacidad de recreación de una atmósfera: gris y húmeda a veces, negra y opresiva otras. Tardi maneja con sus grises diferentes texturas que inundan al lector de información que no se lograría con una paleta de colores ilimitada. El mundo que nos explica, el de las trincheras de la I Guerra mundial y las ciudades arrasadas de la vieja Europa, es un mundo en grises. Así pues, yo pensé también: el mundo que quiero explicar, el de las minas de carbón del norte, con sus ríos sucios, el hollín flotando sobre las chimeneas y la España previa a la Guerra civil, es también un mundo en grises. La influencia de varios títulos de Tardi, como C'était la guerre des tranchées (2001) o Le cri du peuple (2004) que narra la tragedia de la "Comuna de París" de 1871, son referencias evidentes que he utilizado, a veces más conscientemente, y a veces sin apenas percibirlo, en las páginas de La balada del norte. De Tardi he aprendido que un autor de cómic puede exagerar los rasgos de los personajes que dibuja hasta llegar a la caricatura sin que esto 
reste un ápice de dramatismo a la historia. Que la utilización de un sistema clásico y simple de las viñetas no impide una narración vibrante y emotiva. Y que para narrar un evento histórico de primer orden no basta con dibujarlo, no basta con dibujarlo bien, hay que llegar más allá: hay que quererlo todo. Hay que recrear la arquitectura de las calles o los paisajes en los que el hecho histórico sucede, saber qué periódico leía la gente que paseaba por aquellas calles, cuánto costaba ese periódico, qué ropa vestía esa gente, de qué hablaba, qué tabaco fumaba, cómo maldecía y qué anhelaba en aquella vida miserable sin final feliz que rescatamos del olvido para retratarla en una viñeta y entregársela al lector de hoy. Que juzgue el lector el resultado. 
